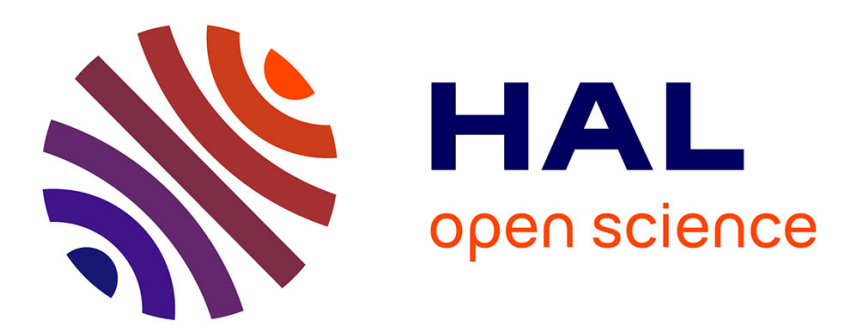

\title{
"Sex in marriage is a divine gift": For whom? Evidence from the Manila contraceptive ban
}

Christelle Dumas, Arnaud Lefranc

\section{To cite this version:}

Christelle Dumas, Arnaud Lefranc. "Sex in marriage is a divine gift": For whom? Evidence from the Manila contraceptive ban. World Bank Economic Review, 2016, 10.1093/wber/lhw055 . hal00867874

\section{HAL Id: hal-00867874 \\ https://hal.science/hal-00867874}

Submitted on 30 Sep 2013

HAL is a multi-disciplinary open access archive for the deposit and dissemination of scientific research documents, whether they are published or not. The documents may come from teaching and research institutions in France or abroad, or from public or private research centers.
L'archive ouverte pluridisciplinaire HAL, est destinée au dépôt et à la diffusion de documents scientifiques de niveau recherche, publiés ou non, émanant des établissements d'enseignement et de recherche français ou étrangers, des laboratoires publics ou privés. 


\title{
"Sex in Marriage is a Divine Gift": For whom? Evidence from the Manila contraceptive ban
}

\author{
Christelle DUMAS* Arnaud LEFRANC ${ }^{\dagger}$
}

July 3, 2013

\begin{abstract}
We analyze the tradeoff between child quantity and quality in developing countries by estimating the effect of family size on child education in urban Philippines. To isolate exogenous changes in family size, we exploit a policy shock: in the late 1990s, the mayor of Manila enacted a municipal ban on modern contraceptives. Since other comparable cities in the Manila metropolitan area were not affected by the ban, this allows us to implement a difference-in-difference estimation of the effect of family size. We also exploit the fact that older mothers were less likely to become pregnant during the ban. Our results indicate that the contraceptive ban led to a significant increase in family size. They also provide evidence of a quality-quantity tradeoff : increased family size led to a sizable decrease in school performance.
\end{abstract}

Keywords: Fertility, family size, human capital investment, quantity-quality tradeoff, Philippines.

JEL Codes: J13, J18, J24, O10.

${ }^{*}$ Université de Lorraine, BETA, Nancy, F-54000, France and THEMA. Email: christelle.dumas@univ-lorraine.fr. This research received financial support from the French National Research Agency, under the grant TRANSINEQ (ANR-08-JCJC-009801). We thank Marie Baguet for excellent research assistance.

${ }^{\dagger}$ Université de Cergy-Pontoise, THEMA, and IZA, 33 Boulevard du Port, F-95011 Cergy-Pontoise. Email: arnaud.lefranc@u-cergy.fr 


\section{Introduction}

High fertility rates are often seen as a major cause of persistent poverty, especially in developing countries. At the microeconomic level, this view largely rests on the idea of a trade-off between family size and child quality introduced by Becker's fertility models (Becker, 1960; Becker and Lewis, 1973; Becker and Tomes, 1976). A rise in family size mechanically raises the cost of a given average child quality, which would induce parents to reduce per capita monetary and time investment in their children. As a consequence, a high fertility rate should lead to lower child quality, as measured for instance by the level of child human capital (e.g. education, health), provided that family resources are important constraints in the accumulation of child human capital. This idea lies at the heart of the family planning interventions that are often implemented in developing countries.

The objective of the present paper is to estimate the causal effect of family size on child quality, by exploiting a policy change that occurred recently in the Philippines. In the early 2000s, the city of Manila enacted a ban on modern contraception. This policy change offers a way to address the the endogeneity of family size that typically plagues the estimation of the quality-quantity tradeoff. We exploit this shock to examine the effect of family size on the educational outcomes of the children of families exposed to the contraceptive ban.

As discussed in various papers, empirically assessing the extent to which family size hinders investment in child quality indeed raises important endogeneity issues. For a variety of reasons, families with a greater number of children might have a lower preference for child quality or lower endowments in key inputs of the child human capital accumulation process. Hence, a major challenge for estimating the causal effect of family size on child investment and related family choices is to isolate exogenous variations in family size. Starting with the work of Rosenzweig and Wolpin (1980), most papers in the recent literature tend to use twin birth, sex of the first child and gender composition of children as exogenous sources of variations in family size (Black, Devereux, and Salvanes, 2005; Angrist, Lavy, and Schlosser, 2005; Cáceres-Delpiano, 2006; Conley and Glauber, 2006; Ponczek and Souza, 2012; Li, Zhang, and Zhu, 2008). This estimation strategy raises several issues. In particular, relying on twin births raises the concern that twins might represent a very special form of family size increase, as discussed for instance in Rosenzweig and Zhang (2009). Most of these articles find that the effect of the household size on children's human capital is close to zero.

Alternatively, a handful of papers have exploited changes in governmental policies regarding family planning and fertility as a way to isolate exogenous changes in family size. This is the case in particular in China, where some authors have exploited variations (in particular at the geographic level) in the applications of the so-called One-Child policy. Qian (2010) finds that 
having a second child benefits rather than disadvantages the first child. Another example of this approach is given by Joshi and Schultz (2007) who evaluate the impact of an intensive family planning and child health program in Bangladesh. The impact evaluation of the program gives a totally different picture, with large effects of the intervention on mothers' and children's human capital. However, this paper cannot provide evidence on the quantity for quality trade-off since the intervention affects many other dimensions than the fertility outcomes.

To summarize, empirical evidence do not seem to provide much support for Becker's conjecture of a quantity-quality trade-off, at least in the case of developed countries (Norway, US, Israel). For low or intermediate income countries (India, China, Brazil) the effect seems quantitatively small. Several factors might explain why the effect of family size varies between rich and poor countries: first, the extent of the trade-off might depend on the level of family resources, as discussed for instance in Kumar and Kugler (2011); second, child benefits offered in richer countries might mitigate the effect of increases in the family size; third, the marginal effect of family size might be not be constant and could vary with family size, which itself varies, on average, with economic development. Considering the last argument, one should emphasize the relatively low fertility rate observed in countries like India, China and Brazil. Therefore, it seems of great importance to assess the extent of the quantity-quality trade-off in countries that have not completed their demographic transition and where the family size remains high.

Our paper offers a contribution to the assessment of the quantity-quality trade-off in the context of a high-fertility country, the Philippines. We exploit a change in family planning policy that was implemented locally, around year 2000, to estimate the causal effect of family size on children outcomes, in particular education. The change in family planning we study is somewhat unusual. In most developing countries, family planning policy has been aiming at promoting the availability of birth control methods. On the contrary, the policy change we study had the opposite effect of reducing birth control possibilities. In the late 1990s, the city of Manila enacted a municipal order that forbid the distribution of modern contraceptive methods in local health facilities. The ban was explicitly motivated by ideological consideration and can be seen as an exogenous fertility shock.

We rely on this policy change to study the effect of family size on human capital investment. This approach essentially amounts to compare the outcomes of children growing up before and after the contraceptive ban, and to relate these changes in outcomes to changes in family size induced by the contraceptive ban. Since families affected by the ban are observed about 10 years later than families not affected, we account for endogenous trends in fertility and other outcomes, by comparing the population of Manila with two counterfactuals. The first one is the neighbor municipality of Quezon 
city and is also the former capital of the Philippines. The second comparison group is the rest of the municipalities of the National Capital Region. Both control groups are comparable to Manila in many respects but are politically independent from Manila city and were not subject to the contraceptive ban. In addition, we exploit the fact that older mothers were less likely to become pregnant during the ban. This strategy, akin to a triple-difference estimator, allows for the possibility of age-specific as well as city-specific trends. Our analysis is based on Census data for 1990, 1995, 2000 and 2007. We also rely on survey data covering various additional outcomes such as health and fertility choices (Demographic and Health Surveys collected in 1993, 1998, 2003 and 2008) and family living conditions (Annual Poverty Indicators Surveys). We find evidence that the contraceptive ban led to a small but significant increase in family size, which had a sizable, negative impact on child education. We also show that the women who were the most affected by the ban were on average more educated.

In the rest of the paper, we first provide some institutional background information on fertility and family planning in the Philippines and present in more details the Manila contraceptive ban (section 2). We next discuss our identification strategy in section 3 . We then turn to the empirical analysis in section 4 and focus on two main issues. The first one is the estimation of the effect of the ban itself on fertility and family size. The second one is the effect of family size on the probability for a child to repeat grades in school. Lastly, we discuss the robustness and the external validity of our findings in section 5 .

\section{Fertility, birth control and the contraceptive ban in the Philippines}

We first describe the fertility and contraception behavior in the Philippines, then provide details on the Manila contraceptive ban and discuss how it can be used it to identify the quantity-quality trade-off.

\subsection{Fertility and contraception in the Philippines}

Filipino women have a high fertility rate. According to national statistics, in 1999, 40 to 49 year old married women had on average 4.6 children. However, as shown in Table 1, this figure is as high as 5.9 for women belonging to the poorest quintile, against 3.5 for the richest ones.

This high fertility rate is associated with a relatively low usage of contraceptives. Table 2 shows that only half of women try to limit their fertility one way or another. Only one woman out of three uses a modern method. Again, this is unevenly distributed among women, with only $28 \%$ of women in the bottom quintile resorting to contraceptives against $36.5 \%$ for women 
Table 1: Mean children ever born to women 40-49 years by asset index quintile, 1999

\begin{tabular}{cccccc}
\hline \hline Poorest & L. middle & Middle & U. middle & Richest & Total \\
5.9 & 5.2 & 4.9 & 3.9 & 3.5 & 4.6 \\
\hline \hline
\end{tabular}

Note: Family Planning Survey, 1999. Coverage: Filipino households. Source: Orbeta, 2005.

from the highest quintile. This low use of contraceptives seems to arise primarily from the difficulties in accessing contraceptives, rather from individual choice. For instance, Orbeta (2005) documents the gap between actual and wanted fertility and reports that the desired fertility of women in the poorest quintile is on average 2 children lower than their actual fertility. For women in the highest quintile, this seems less the case, with a gap between actual and desired fertility of .5 child.

Table 2: Contraceptive methods by asset index quintile, 2002

\begin{tabular}{cccc}
\hline \hline & No method & Modern & Traditional \\
Total & 51.2 & 35.1 & 13.8 \\
& & & \\
Poorest & 58.5 & 28.0 & 13.5 \\
Lower middle & 50.8 & 35.9 & 13.3 \\
Middle & 46.2 & 39.0 & 14.8 \\
U. middle & 49.6 & 36.8 & 13.7 \\
Richest & 49.9 & 36.5 & 13.6 \\
\hline \hline
\end{tabular}

Note: Family Planning Survey, 2002. Coverage: Filipino households. Source: Orbeta, 2005.

The top line of table 3 also provides evidence on the type of contraceptive methods used, together with the source of supply. Two thirds of women using contraception take oral contraceptives. Intra-uterine devices (IUD) and injections are also commonly used, while condoms are hardly used. The table also shows that for a majority of households, modern contraceptives are primarily supplied by public institutions. Even more striking are the differences between the poorest and richest women in this respect. Nearly $90 \%$ of the women in the poorest group who use contraceptives get them in a public hospital or a public health center. By comparison, only half of contraceptives are provided by public sources for higher quintile women. 
In any case, we expect a reduction in public provision of contraceptives to affect most households.

Table 3: Use of modern contraceptives, 2002

\begin{tabular}{|c|c|c|c|c|c|c|}
\hline \multicolumn{7}{|c|}{ Type of contraceptives used } \\
\hline & Pill & IUD & Injection & Condom & Ligation & Total \\
\hline & $65.6 \%$ & $16.8 \%$ & $11.3 \%$ & $6 \%$ & $0.2 \%$ & $100 \%$ \\
\hline \multicolumn{7}{|c|}{ Share of the population using contraceptives resorting on public provides } \\
\hline Philippines & 65.4 & 74.9 & 92.9 & 41.0 & 72.8 & 70.1 \\
\hline Poorest & 87.8 & 86.1 & 96.8 & 78.5 & 84.3 & 87.9 \\
\hline Richest & 39.8 & 53.5 & 81.5 & 19.0 & 60.0 & 50.3 \\
\hline
\end{tabular}

Note: Coverage: Filipino households. Source: Our own calculation for the first line (Family Planning Survey, 2006); Orbeta (2005) for the rest of the table (Family Planning Survey, 2002).

Lastly, we should note that the organization of and responsibility for family planning services has been devolved in 1991 from the central government to the local governments. Furthermore, there is little national guidance on what type of services should be provided by the local governments (Orbeta, 2005). As a result, households living in different places do not face the same birth control options and some may largely rely on NGOs when family planning is under-provided by local governments.

\subsection{The Manila ban on contraceptives}

In 1998, Jose Livioko Atienza was elected in Manila, the capital city of the Philippines. He held office until 2007 and had been before vice-mayor of Manila for 6 years. As founder of the BUHAY Party, an anti-abortion organization that "acknowledges the sanctity and value of human life", he is an active participant of the "pro-life" movement, opposing birth-control. ${ }^{1}$ Echoing the doctrine of the Philippine Roman Catholic church, he enacted in 2000 the Manila City Executive Order \# 003 which stipulates that:

"The City promotes responsible parenthood and upholds natural family planning not just as a method but as a way of selfawareness in promoting the culture of life while discouraging the

\footnotetext{
${ }^{1}$ http://www. buhaypartylist.com.ph/
} 
use of artificial methods of contraception like condoms, pills, intrauterine devices, surgical sterilization, and other."

In practice, as noted by many observers, this led to a ban of modern contraceptives from public health facilities and city heath centers (Center for Reproductive Rights, 2007). In addition, evidence also indicate that, as a result of the mayor's policy, NGOs and private providers have been harassed and intimidated into ceasing to provide family planning services. This campaign against birth control even extended to traditional herbalists supposed to sell contraceptive concoctions in the city of Manila. The Manila government hospitals (the Dr. Jose Fabella Memorial Hospital and the Philippines General Hospital) were the two exceptions to the ban. However, very little information was provided to women: even acknowledging that some contraceptives were available in these governmental hospitals was considered by most doctors as violating the executive order enacted by the mayor. This resulted in a very difficult and a more expensive access to contraceptives (either due to higher direct costs or to higher opportunity costs). The report from the Center for Reproductive Rights (2007) quotes several women in distress as a consequence of the new policy:

"I feel anxious and fearful of the chance of getting pregnant if I don't have money to buy pills, unlike before when I used to get injectables for free, which were very convenient and effective for months."

There is also evidence that the public provision of contraceptives became scarcer even before the enactment of the 2000 ban. Several women attest to the fact that as early as 1997, the city of Manila had decided to substantially reduce its family planning services.

"After the birth of my second child, [...] the attending staff $[\ldots]$ advised me to try DMPA, the injectable. ${ }^{2}$ For two years I was using DMPA. I found it not only convenient by having the injection every three months, but also cheap because at that time, I got the injectable from the health center for free. I paid only 10 pesos for the disposable needle. In 1997, the staff at the health center $[. .$.$] warned me that it was going to be my last$ injection. "The mayor is pro-life now and will ban all family planning supplies and services in all health centers and hospitals in Manila."

In the rest of the paper, we will need to take this early reduction in access to contraceptives into account and we will confirm empirically that the use of contraceptives in Manila had already decreased in 2000.

\footnotetext{
${ }^{2}$ Depot Medroxyprogesterone Acetate (DMPA).
} 
By comparison, surrounding cities in the Manila Metropolitan area were not subject to the ban since they constitute independent municipal jurisdictions. A map of the Manila Metropolitan area, also know as the National Capital Region (NCR) is given in figure 1. Among these neighboring cities, an interesting comparison point is given by Quezon City. Quezon City borders Manila. It was the capital city of the Philippines until 1976 and is, in many respect, similar to Manila (as discussed below) although the provision of family planning services differs.

Figure 1: Metro Manila map

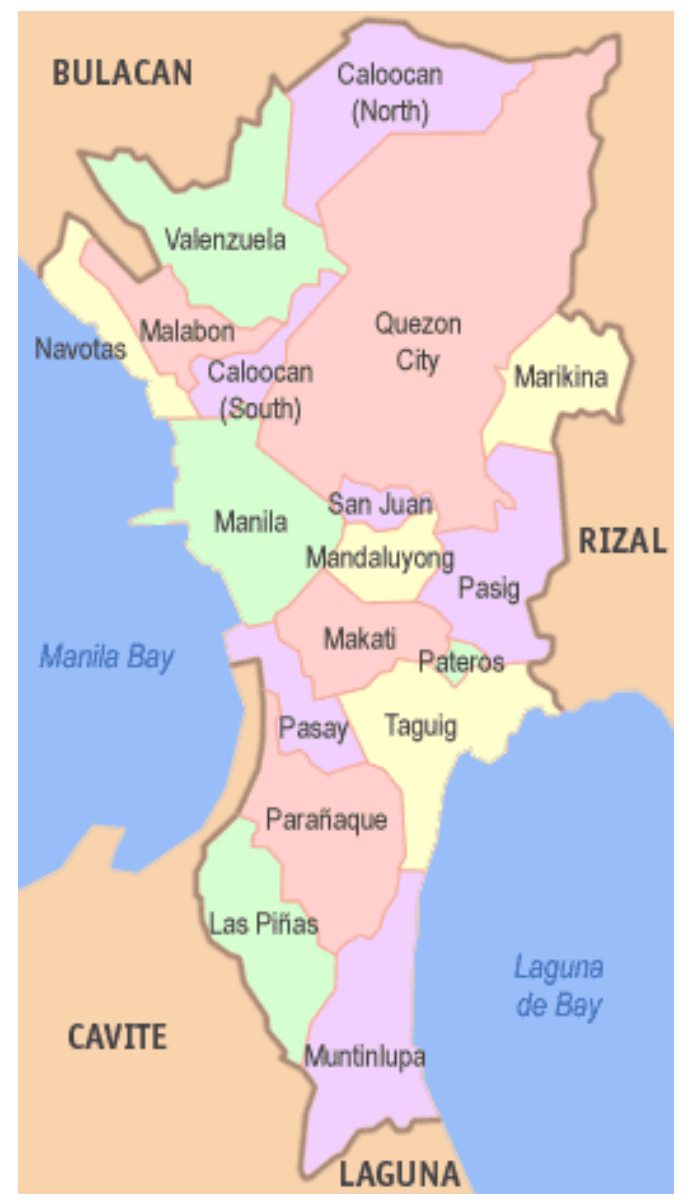

Figure 2, compare the rates of modern contraceptive use of women 20 to 45 years old in various cities of the National Capital Region between 1993 and 2008, based on data from the Demographic and Health Surveys. ${ }^{3}$ All cities in the National Capital Region, except for Manila, exhibit a clear

${ }^{3}$ See below for a description. 
increasing trend in contraceptives use between 1993 and 2008. The data for Manila shows a fall from $35 \%$ to $30 \%$ between 1993, before the election of Atienza, and 2003, three years after the ban was enacted. A fall is also observed between 1993 and 1998, i.e. before the ban was officially enacted. Lastly, in 2008 we observe in Manila a large increase in the use of contraceptives, and the level attained is broadly the one that would have been reached in 2008 if the trend had been the same than the one that prevailed in the rest of the NCR. One specificity of the evolution in Quezon City should also be stressed: 2003 displays a very high level of contraceptives use, compared to adjacent years. This might be consistent with some NGOs previously located in Manila relocating their activity in Quezon City. Three lessons can be drawn from these results. First, the policy of the municipality of Manila against birth control brought up a reduction in the rate of contraceptive use that runs against the dominant trends. Second, it confirms that the restrictions placed upon contraceptives availability took place as soon as 1997, i.e. a few years before the enactment of the executive order. Third, neighboring cities, in particular Quezon City, might have been positively affected by the ban, through a partial relocation of family planning services. If so, the comparison of Manila with other cities might overstate the direct effect on fertility of the Manila. However, this remains an exogenous source of variation in women's fertility and does not invalidate the identification strategy.

Figure 2: Rate of use of modern contraceptives: women 20 to 45 years old

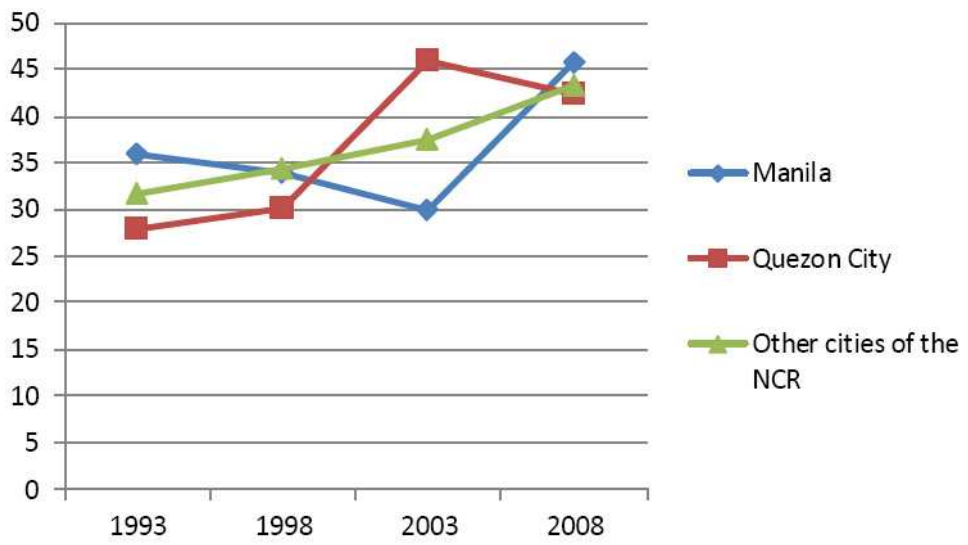




\section{Methodology}

\subsection{Identification}

We rely on the Manila ban on contraceptives to identify the causal effect of the quantity of children on their quality. Our presumption is that preventing households from accessing contraceptives should impact their fertility. As a result, the implementation of the ban will result in an exogenous increase in family size between households who were exposed to the ban and households who were not.

A natural way of exploiting the effect of the ban would be to compare different cohorts of Manila women having their fertility period before or after the ban. However, endogenous trends, both in fertility and in investment in child human capital, might operate that would likely compromise the identification of the effect of the ban on fertility as well as the estimation of the causal effect of family size on child quality.

Our analysis relies on two different identification strategies. The first one is a simple difference-in-difference strategy obtained by comparing changes in fertility and child outcomes, before and after the ban, in Manila and in a comparison city. Using a control city allows to account for trends in both fertility behavior and in schooling outcomes, assuming that trends in Manila and the comparison city are similar. The difference-in-difference approach also allows to account for city fixed effects. In the sequel, we consider two possible comparison cities. The first one is Quezon City, which, as discussed in the next section, is quite similar to Manila. The second is the rest of the National Capital Region (excluding Quezon City).

The assumption that the trends would have been the same in Manila and the comparison city in the absence of the ban may not be satisfied for a variety of reasons. First, the two cities might be "intrinsically" subject to different trends, owing to idiosyncratic changes in the public provision of education or health occurring at the same time as the ban. Second, the ban might have had endogenous consequences that will affect children's outcomes, independently of the change in their sibship size. For instance, as a result of a rise in fertility triggered by the ban, the schooling system might become congested. If, other things equal, pupils enrolled in overcrowded classes are more likely to face difficulties in learning, the ban will affect children's outcome independently of its effect on family size. For this reason, we implement a second identification strategy, which is akin to a tripledifference ${ }^{4}$. The advantage of this approach is to allow for different trends between Manila and the comparison city. In the triple-difference strategy, the identification relies on the fact that the ban on contraceptives will not have homogenous effects among all women. In particular, the direct effect of

\footnotetext{
${ }^{4}$ This is not a proper triple-difference since the third dimension of differentiation is continuous rather than discrete.
} 
the ban on the number of children will be smaller on older women for reasons owing to the decline in the fertility over the life-cycle, since they are less fertile at any point in time they are exposed to the ban. At the extreme, the effect of the ban on the number of children of women who were very close to the end of their fertility period when the ban was enacted should logically be zero. Hence any change in the outcome of their children will reflect trends in individual outcome that are (potentially) specific to Manila and that operate independently of the number of children in the family. Assuming that these trends are similar across all age groups of Manila women, we can identify the effect of the ban on fertility and schooling outcomes, without relying on the assumption that trends are the same in Manila and Quezon City.

\subsection{Data}

The main data set used in our analysis come from the Philippine Censuses. We rely on the data collected in 1990 and 1995, before the implementation of the Manila ban, and in 2007, after the ban was implemented. We discard data for the year 2000 from our main estimations since they correspond to the early implementation of the ban.

The main advantage of the census is its very large number of observations: for instance Manila has 1.6 millions inhabitants and Quezon City more than 2 millions. This allows us to detect even small effects. However, the information collected is quite limited. For the purpose of the present paper, the main information pertains to the household composition and school attainment (highest grade completed). As a consequence, for assessing the quality-quantity trade-off, one has to focus on the schooling performance of children, as our main variable of interest.

The way we construct our measure of schooling performance and define our sample is constrained by the institutional features of the Philippines educational system, by the dates at which census data are collected as well as the information available in the questionnaire.

Our main objective is to measure the effect of the ban on individuals born before the ban but whose family size might have been affected by the ban. Since the reduction in the supply of contraceptives started as early as 1997, we focus on children born before 1997 and exclude from our sample household members younger than 10, for reasons discussed below. We also exclude children aged 16 and higher, since decisions to leave the family household might be endogenous and raise sample selection issues. ${ }^{5}$

Our main educational outcome is the gap between the highest grade attended and the grade that the child should currently be attending under a normal curriculum if he were still enrolled in school. In the Philippines,

\footnotetext{
${ }^{5} \mathrm{An}$ additional reason is that this age group is likely to have been less affected by additional children born because of the ban, to the extent that they developed their early skill before the enacting of the ban.
} 
compulsory schooling extends from the ages of 7 to 12 years old. Our variable is denoted by gap, where gap =age - 7 - highest grade attended. For children continuously enrolled in school, a negative value of the gap indicates grade repetition. For others, it indicates either early drop out or grade repetition. However, the enrollment rate in the National Capital Region is very high ${ }^{6}$ which suggests that the gap variable mostly reflects grade repetition. ${ }^{7}$

One difficulty in implementing this measure of educational outcomes arises from the fact that the precise date of birth is not collected in the census but only the age at the time of the survey. This makes the above defined gap slightly ambiguous. Take a child who is 8 years old at the time of the census and who is enrolled in the first grade of primary school. Since the normal age for entry in first grade is 7 , this child might be one year behind normal curriculum. Alternatively he could be on time but born in the beginning of the calendar year. Hence, a one year gap is ambiguous. On the contrary, a two years gap is an unambiguous indication of grade repetition and/or early drop-out. ${ }^{8}$ For this reason, we measure educational outcomes by means of a dummy variable equal to one if gap is strictly less than -1 . Our dependent variable is therefore: $Y=\mathbf{1}($ gap $<-1)$.

Another limitation of the Censuses is that only the relationship to the household head is recorded. As a consequence, we need to make some assumptions to match a child to his/her mother. We will therefore focus on children who are recorded as children of the household head and consider that the household head's wife is their mother. ${ }^{9}$ This is not a very strong assumption since Philippines is a very Catholic country and there are very few divorces (and remarriages). However, this compels us in excluding from our sample households where more than two generations cohabit and where a grand-parent is chosen as head. Furthermore, we impose a restriction on the age gap between the presumed mother and the household children for two reasons. First, our estimation relies on variation driven by the mother's age and we restrict this range so as to make sure not to capture specificities due to very young/old women. Second, this strengthens our assumption that the woman is indeed the mother. Specifically, we require that the mother was aged between 20 to 30 years old at the time of the child's birth. Since the age range for children is 11-16, this implies that our sample is restricted to mothers aged 31 to 46 at the time of the survey.

\footnotetext{
${ }^{6}$ The enrollment rate of children in the $7-12$ age range is equal to $95 \%$ at each age in 2007 ; it gradually falls to $85 \%$ for 15 years old children and drops at $70 \%$ for 16 years old children.

${ }^{7}$ Of course, these two outcomes should ideally be distinguished. Unfortunately, since school enrolment is only reported in the 2007 census it is not possible to distinguish grade repetition from school dropout.

${ }^{8}$ In fact, a two years gap indicates a child who is one year or two years behind the standard curriculum.

${ }^{9}$ We do not need to make any assumptions when the household head is female.
} 
Table 4: Comparison of Manila, Quezon City and the other cities of the National Capital Region (mean values)

\begin{tabular}{|c|c|c|c|}
\hline \multicolumn{4}{|c|}{ Panel A: Census, women aged 31 to 46 years old, 1995 (152800 obs) } \\
\hline & Manila & Quezon City & Rest of the NCR \\
\hline Years of education & 9.45 & $9.46^{* * *}$ & $9.31^{* * *}$ \\
\hline Age & 37.95 & $37.67^{* * *}$ & $37.73^{* * *}$ \\
\hline In couple & 0.89 & $0.91^{* * *}$ & $0.92^{* * *}$ \\
\hline Number of children (at home) & 2.73 & $2.77^{* * *}$ & $2.80^{* * *}$ \\
\hline \multicolumn{4}{|c|}{ Panel B: Demographic and Health Surveys, women aged 31 to 46 years old, 1993 and 1998 (1140 obs) } \\
\hline & Manila & Quezon City & Rest of the NCR \\
\hline Use of contraceptive pill & 0.04 & 0.04 & 0.05 \\
\hline Husband or wife has been sterilized & 0.20 & 0.16 & $0.15^{* *}$ \\
\hline Uses a modern contraceptive method & 0.50 & 0.45 & 0.48 \\
\hline Not catholic & 0.10 & $0.18^{* *}$ & 0.10 \\
\hline Number of births in the last 5 years & 0.44 & 0.43 & 0.47 \\
\hline Has had a terminated pregnancy in the last 5 years & 0.18 & 0.17 & 0.22 \\
\hline Marriage to 1st birth interval (in months) & 16.35 & 16.6 & $19.3^{*}$ \\
\hline Age of respondent at 1st birth (in years) & 23.04 & $23.88^{*}$ & 23.5 \\
\hline \multicolumn{4}{|c|}{ Panel C: Annual Poverty and Income Survey, households of the NCR, 1998 (4250 obs) } \\
\hline & Manila & Quezon City & Rest of the NCR \\
\hline Children's school participation & 0.953 & 0.963 & 0.945 \\
\hline Child labor participation & 0.029 & 0.016 & 0.019 \\
\hline Female labor force participation & 0.500 & $0.557^{*}$ & 0.510 \\
\hline Household's 4 months income (pesos) & 106823 & $128495^{*}$ & 116089 \\
\hline Total expenditures & 88859 & $97730^{*}$ & 93574 \\
\hline \multicolumn{4}{|l|}{ Panel D: Census, 10\% subsample, 2000 (195000 obs) } \\
\hline & Manila & Quezon City & Rest of the NCR \\
\hline Roof of good quality & 0.93 & $0.94^{* * *}$ & $0.95^{* * *}$ \\
\hline Walls of good quality & 0.33 & $0.48^{* * *}$ & $0.50^{* * *}$ \\
\hline House: no need for repair & 0.73 & $0.77^{* * *}$ & $0.79^{* * *}$ \\
\hline Has electricity & 0.96 & 0.96 & 0.96 \\
\hline Has proper water & 0.95 & $0.96^{* * *}$ & $0.87^{* * *}$ \\
\hline Owns the house & 0.42 & $0.49^{* * *}$ & $0.54^{* * *}$ \\
\hline Has a radio & 0.81 & $0.83^{* * *}$ & $0.83^{* * *}$ \\
\hline Has a tv & 0.81 & $0.83^{* * *}$ & $0.83^{* * *}$ \\
\hline Has a fridge & 0.58 & $0.60 * * *$ & $0.59^{* * *}$ \\
\hline Has a phone & 0.36 & $0.36^{* *}$ & $0.33^{* * *}$ \\
\hline Has a washing machine & 0.43 & 0.43 & 0.43 \\
\hline Has a vehicle & 0.12 & $0.18^{* * *}$ & $0.17^{* * *}$ \\
\hline
\end{tabular}

Note: Stars in column (2) indicates the rejection of the hypothesis that the mean in Manila is equal to the mean in Quezon City; stars in column (3) indicates the rejection of the hypothesis that the mean in Manila is equal to the mean for the Rest of the National Capital Region. ${ }^{* * *} p<0.01,{ }^{* *} p<0.05,{ }^{*} p<.10$. "Terminated pregnancy" includes (illegal) abortion, miscarriages and stillbirths. 
Our analysis also relies on two other data sets. The first one is the set of Demographic and Health Surveys (DHS) collected in 1993, 1998, 2003 and 2008. One of the advantage of these data is to provide information on the use of contraceptives in the different cities of National Capital Region (and throughout the Philippines more generally). The second data set is the Annual Poverty Indicator Survey (APIS) that provides information on household resources and living conditions. Both data sets have small sample sizes located in the National Capital Region and we only used them in order to assess the trends in the use of contraceptives and to compare characteristics of the various municipalities.

As previously discussed, our estimation strategy consists in comparing the evolution at work in Manila with that of neighboring cities. We consider two comparisons groups. The first one is Quezon City. The second one is the rest of the National Capital Region. Before discussing our estimation procedure, we provide in table 4 a set of descriptive statistics in order to compare various outcomes in Manila, and the two comparison groups. We rely on four sources. The 1995 census (panel A), provides statistics for our pre-treatment period. The DHS data collected in 1993 and 1998 allow to compare fertility behavior (panel B) ${ }^{10}$. The APIS data collected in 1998 allow to compare income levels (panel C) ${ }^{11}$. Lastly, the $10 \%$ sample of the 2000 census offers detailed information on assets ownership and quality of housing (panel D).

The results suggests that households are largely similar across the three areas. Given the large sample size in the Census, equality tests reject the hypothesis that the means demographic characteristics are equal. However, the point estimates are remarkably close to each other for age, years of education as well as number of children. This holds more generally for fertility and birth control behavior, as well as economic and housing conditions. In general Quezon City lies closer to Manila than are the other cities, particularly when it comes to women's age and education, fertility and contraception behaviors, which are crucial to us. ${ }^{12}$ Overall, the ex ante degree of similarity between the three areas supports our identification strategy.

\subsection{Estimation}

In order to assess the quantity-quality trade-off, we resort to a two-stage least squares approach. We regress children's outcome on the size of their sibship, where we use the effect of the ban on contraceptive as an instrument for sibship size. We also discuss the first-step and reduced form estimates

\footnotetext{
${ }^{10}$ We pool 1993 and 1998 in order to increase the number of observations, which is quite low otherwise.

${ }^{11}$ APIS data were not collected prior to 1998.

${ }^{12}$ We tried to compare with other cities individually but they do not perform better and are much smaller in size.
} 
that allow to directly assess the effect of the ban on fertility and children's outcomes.

The model we estimate is:

$$
\begin{aligned}
& Y=\alpha_{1} X+\beta K+u \\
& K=\alpha_{2} X+\gamma Z+v
\end{aligned}
$$

The dependent variable $Y$ is the dummy indicator for child's grade repetition; $K$ denotes the number of children in the household and is potentially endogenous; $X$ includes additional control variables and $Z$ denotes the instrument.

As previously discussed, we consider two instrumental variables. The first one is the interaction Manila $\times 2007$. The second one is the interaction Manila $\times$ Mother's age $\times 2007$.

The exogenous covariates $X$ include child's age and its square (older children are more likely to have repeated a grade), mother's age (which affects the number of children ever born to a woman), as well as year and city fixed effects. We also include simple interaction terms between Manila, Mother's age and 2007 when using Manila $\times$ Mother's age $\times 2007$ as an instrument. The repetition rates might differ between Manila and the comparison cities, for instance because of differences in educational policies. If this is the case, the gap in repetition rate will most likely widen with child's age. Indeed, if the ban led to a large increase in the number of children to be enrolled, we would expect the likelihood of falling behind to change in 2007. We therefore control for the interaction between Manila and Child's age effects, as well as for the Manila $\times$ Child's age $\times 2007$ effects. In addition, the child's age and the mother's age variables are correlated. ${ }^{13}$ For the identification relying on the heterogeneity of the effect by mother's age, it is therefore crucial to control for changes taking place in Manila that are heterogenous by child's age.

For the sake of simplicity, given the large number of observations and the restricted range of the explanatory variables, we estimate a linear probability model for our dummy dependent variable $Y$. The first-step equation for $K$, which is also a discrete variable, is likewise estimated by linear regression, to avoid any assumption on the law of the residuals.

Fertility is measured with error since only the number of children present in the household at the time of the census is recorded. Noting that the exogenous variation provided by the ban is the variation in the number of children younger than 10, we focus on this variable rather than the total number of children. Indeed, the number of children younger than 10 in the household is likely to be a good proxy of the past 10 years' fertility.

As already mentioned, we focus on the effect of the contraceptive ban on the educational success of children born before the ban. Henceforth, our

\footnotetext{
${ }^{13}$ Even the more so that our selected sample narrows the age difference between them.
} 
2SLS model is estimated on children aged 11 to 16 years old. In fact, if the effect of the ban varies with unobservable family characteristics, estimating the effect of the ban on children born after the ban would introduce a composition effect, since the distribution of family characteristics would not be comparable between the control and the treatment groups.

One may of course question whether the effect of family size on children born before the ban is representative of the average effect on the whole sample of children (including those born because of the ban). The external validity of our results depends on whether children born due to the ban differ from other children. This issue is discussed in Rosenzweig and Zhang (2009) who show that if newborn children have significantly lower endowments than the average child and if parents reinforce endowments, then the effect estimated on elder children is a lower bound of the average effect and the effect on the newborn children provides an upper bound. They also provide evidence that the two conditions seem to be satisfied in the case of Chinese families. In our case, we cannot compute the effect on the children born due to the treatment, since we are unable to identify them. However, focusing on children older than 11 allows to make sure we identify the lower bound effect (provided that there is reinforcement, as in China). ${ }^{14}$

In the rest of the paper, we also provide OLS estimates for comparison with our 2SLS estimates. One should however emphasize that since IV estimates are Local Average Treatment Effects, one cannot infer from the comparison of OLS and IV estimates the sign of the endogeneity bias. In our case, the LATE will be the impact on the outcome of elder children of one additional sibling for families affected by the ban, i.e. for families that would have avoided an additional pregnancy in the absence of the ban but failed to under the ban ("compliers").

\section{Results}

\subsection{Evidence on the fertility effect of the ban}

We first examine the effect of the ban on women's fertility. Table 5 analyzes the effect of the ban on the number of children younger than 10 years old. The sample comprises all women aged 31 to 40 in Manila and Quezon City in 1997 and $2007 .{ }^{15}$ The table indicates that the ban had a positive but

\footnotetext{
${ }^{14}$ In our case, such a mechanism could take place if the additional children receive lower endowments (if the mothers' pregnancies succeed to each other closely for instance, babies' birth weight is lower) and/or lower investment (families may choose to under-invest in unwanted children). However, we do not have strong priors nor evidence of such effects: the sample in the DHS data is too small to detect any effect on health outcomes due to the ban.

${ }^{15}$ In this section, the unit of analysis is the mother, unlike the rest of the section that uses children as the unit of observation. The results are, however, similar. We defer to the next section the comparison of Manila with the rest of the NCR.
} 
limited effect on fertility. Assuming that fertility trends were similar between Manila and Quezon City (column 1), the table indicates that the ban rose the number of children in Manila by .0977, compared to Quezon City.

This is relatively small and can be explained by a variety of reasons. First, some women may have avoided pregnancies thanks to the use of an intra-uterine device or ligation performed before 1997. As documented in table 4 this is quite common in the National Capital Region. Second, women may have had access to contraceptives through government hospitals, neighboring cities and private providers. Third, unwanted pregnancies may have ended up in abortion. ${ }^{16}$ One should underline that these strategies entail a significant monetary, psychological and health cost that can unfortunately not be assessed here given data limitations.

Because these options seem to have been, at least partially, available to women, we may suspect that the treatment was not purely random. If so, one may also suspect that the effect measured on the compliers may not be representative of the trade-off on the whole population. We address this issue in section 5.2 and show that, if anything, IV estimates would tend to understate the extent of the trade-off on the entire population.

The rise in the number of children aged less than 10 years old in postban Manila varies with women's age. This appears in column 2, where we interact Manila $\times 2007$ with mother's age. The table implies that women aged 21 in 1997 (31 in 2007) had .17 additional children. ${ }^{17}$. For a women aged 36 in 1997, the ban resulted in an estimated additional .02 children. These results are consistent with the ban having a stronger effect on women with the highest "instantaneous" fertility and the longest remaining fertility period at the time the ban was implemented. The effect is estimated to be zero for women aged 48 years old in 2007. Considering that these women were aged 38 at the time of the election of Atienza as Mayor of Manila and 41 at the time of enactment of the ban, these estimates seem plausible, although the fertility period for women is often consider to stretch up to age 50. Also, when analyzing the age at which we estimate the effect of the ban to be zero, one should also keep in mind that the Manila $\times 2007$ dummy may also capture other changes in fertility behavior specific to Manila that took place between 1995 and 2007. Altogether, these results are consistent with the ban having a differentiated effect on fertility according to mother's age and support our second identification strategy.

\footnotetext{
${ }^{16}$ Abortion is illegal in the Philippines and is punished by imprisonment. However, it is widespread. Darroch, Singh, Ball, and Cabigon (2009) estimates that, in 2008, in the National Capital Region, $60 \%$ of pregnancies were unintended and half of those unintended pregnancies resulted in abortion. Juarez, Cabigon, Singh, and Hussain (2005) finds that the abortion rate has been increasing over the period 1994-2000 in the National Capital Region.

${ }^{17}$ Since age in table 5 is centered at 38 , the effect for a 31 year old mother is given by $0.100+(31-38) \times(-.0101)=0.17$.
} 
Table 5: Effect of the ban on women's fertility (women 31-46 years old)

\begin{tabular}{lcc}
\hline \hline & \multicolumn{2}{c}{ Number of children under 10} \\
& $(1)$ & $(2)$ \\
Mother's age & $-0.141^{* * *}$ & $-0.149^{* * *}$ \\
Manila & $(0.000229)$ & $(0.000445)$ \\
& $-0.165^{* * *}$ & $-0.164^{* * *}$ \\
2007 & $(0.00297)$ & $(0.00298)$ \\
& $-0.0420^{* * *}$ & $-0.0463^{* * *}$ \\
Manila $\times 2007$ & $(0.00263)$ & $(0.00263)$ \\
& $0.0977^{* * *}$ & $0.100^{* * *}$ \\
Manila $\times$ Mother's age & $(0.00416)$ & $(0.00417)$ \\
& & $0.00249^{* * *}$ \\
Mother's age $\times 2007$ & & $(0.000673)$ \\
& & $0.0164^{* * *}$ \\
Mother's age $\times$ Manila $\times 2007$ & & $(0.000594)$ \\
Constant & & $-0.0101^{* * *}$ \\
& & $(0.000937)$ \\
Observations & $1.959^{* * *}$ & $1.958^{* * *}$ \\
R-squared & $(0.00196)$ & $(0.00196)$ \\
\hline \hline
\end{tabular}

Note: Standard errors in parentheses. ${ }^{* * *} \mathrm{p}<0.01, * * \mathrm{p}<0.05, * \mathrm{p}<0.1$. Mother's age is centered at 38 .

\subsection{First-stage and reduced form estimates}

Table 6 provides first-stage regressions (columns 1 and 2). The only difference between these results and those commented in the previous section is that the observation unit is now the child rather than the mother, and the dependent variable is now the number of siblings younger than 10 years old, rather than the number of children of that age.

Panel A displays the results for the comparison of Manila and Quezon City between 1995 and 2007. The results are of course very similar to those of table 5. Panel B displays the results for the comparison between Manila and other cities of the National Capital Region. The effect of the ban on the number of younger siblings is rather similar, although slightly lower, when using this alternative control group. In both cases, the F-statistics are well 
Table 6: Effect of the ban on fertility and grade repetition (children 11-16 years old)

\begin{tabular}{|c|c|c|c|c|}
\hline \multicolumn{5}{|c|}{ Panel A: Manila vs Quezon City } \\
\hline & \multicolumn{2}{|c|}{ \# of children under 10} & \multicolumn{2}{|c|}{ Grade repetition } \\
\hline & $(1)$ & $(2)$ & & $(4)$ \\
\hline \multirow[t]{2}{*}{ Manila $\times 2007$} & $0.0562^{* * *}$ & $0.0549^{* * *}$ & $0.0111^{* * *}$ & $0.0149^{* * *}$ \\
\hline & $(0.0116)$ & $(0.0122)$ & $(0.00374)$ & $(0.00393)$ \\
\hline \multirow[t]{2}{*}{ Mother's age $\times$ Manila $\times 2007$} & & $-0.0105^{* * *}$ & & $-0.00139^{*}$ \\
\hline & & $(0.00245)$ & & $(0.000791)$ \\
\hline F-stat & 23.49 & 18.17 & & \\
\hline Observations & 433,036 & 433,036 & 433,036 & 433,036 \\
\hline R-squared & 0.084 & 0.084 & 0.028 & 0.029 \\
\hline \multicolumn{5}{|c|}{ Panel B: Manila vs other cities of the NCR } \\
\hline & \multicolumn{2}{|c|}{ \# of children under 10} & \multicolumn{2}{|c|}{ Grade repetition } \\
\hline & $(1)$ & $(2)$ & $(3)$ & $(4)$ \\
\hline Manila $\times 2007$ & $0.0420^{* * *}$ & $0.0397^{* * *}$ & -0.00439 & -0.000764 \\
\hline & $(0.0111)$ & $(0.0118)$ & $(0.00349)$ & $(0.00369)$ \\
\hline \multirow[t]{2}{*}{ Mother's age $\times$ Manila $\times 2007$} & & $-0.00865^{* * *}$ & & $-0.00125^{*}$ \\
\hline & & $(0.00220)$ & & $(0.000691)$ \\
\hline F-stat & 14.22 & 15.38 & & \\
\hline Observations & 924,942 & 924,942 & 924,942 & 924,942 \\
\hline R-squared & 0.078 & 0.078 & 0.029 & 0.029 \\
\hline
\end{tabular}

Note: Standard errors in parentheses. ${ }^{* * *} \mathrm{p}<0.01,{ }^{* *} \mathrm{p}<0.05{ }^{*} \mathrm{p}<0.1$. Mother's age is centered at 38 . The effect of the ban (Manila $\times 2007$ ) is computed for an 11 years old child. Additional controls include: child's age, its square, child's age interacted with the Manila dummy and interacted with Manila $\times 2007$, child's gender, mother's age and year and city fixed effects. F-stats in column (1) test for the significance of Manila $\times 2007$, while F-stats in column (2) test for the significance of Mother's age $\times$ Manila×2007 only.

above 10 .

Columns 3 and 4 report the reduced form estimates of the contraceptives ban. In most cases the ban seems to be associated with poorer educational outcomes, as captured by a rise in the probability of grade repetition or dropout. The average repetition rate increases significantly in post-ban Manila, when compared to Quezon City, although the effect is not significantly different from zero when comparing Manila with other cities of the NCR. Furthermore, the post-ban Manila-specific increase in grade repeti- 
tion seems to be higher, conditional on child age, for children's with older mothers. This holds for both comparison groups.

\subsection{Instrumental variables estimates}

Table 7 provides OLS and Instrumental variables (2SLS) coefficient estimates for the regression of grade repetition on the number of siblings. OLS estimates indicate a moderate negative impact of the quantity of children on child quality: one additional child is associated to an increase by $3.75 \%$ points of the likelihood to be held back by at least one grade, where the average probability of grade repetition is $20 \%$ in the sample.

Table 7: Effect of the number of children on grade retention (children 11-16 years old)

Panel A: Manila vs Quezon City

(1)

OLS

Instrument

\# of children under 10

$0.0375^{* * *}$

$(0.000487)$
Grade repetition

(2)

2SLS

2SLS

Manila $\times 2007 \quad$ Manila $\times$ Mother's age $\times 2007$

$0.197^{* * *} \quad 0.133^{*}$

$(0.0739) \quad(0.0784)$

Observations

433,036

433,036

433,036

R-squared 0.042

Panel B: Manila vs other cities of the NCR

(1)

OLS

Instrument

\# of children under 10

$0.0361^{* * *}$
$(0.000324)$

924,942

0.042

R-squared
Grade repetition

2SLS

2SLS

Manila $\times 2007 \quad$ Manila $\times$ Mother's age $\times 2007$

$-0.104 \quad 0.145^{*}$

(0.0906)

$(0.0841)$

Observations

924,942

924,942

Note: Standard errors in parentheses. ${ }^{* * *} \mathrm{p}<0.01,{ }^{* *} \mathrm{p}<0.05,{ }^{*} \mathrm{p}<0.1$. Additional controls include: child's age, its square, child's age interacted with the Manila dummy and interacted with Manila $\times 2007$, child's gender, mother's age, year and city fixed effects and the interaction Manila $\times 2007$.

Columns 2 and 3, panel A, provide IV estimates for the comparison of Manila and Quezon City. Under the hypothesis of similar trends (in educa- 
tion and fertility) between the two cities, the IV estimate indicate a much higher impact of increased family size. Increasing the number of siblings aged less than 10 by one child raises the repetition rate by 20 percentage points. In other words, raising the number of siblings younger than 10 by $75 \%$ leads to a doubling of the repetition rate. Of course, as discussed in section 3.1, there are reasons to doubt that Manila and Quezon city had similar trends, in particular with regard to educational outcomes. The IV estimates provided in column 3, which allow for different trends between Manila and Quezon city, indicate a smaller, but nevertheless substantial impact of family size on grade repetition. According to these estimates, one additional child increases by 13 percentage points the probability of repeating a grade or dropping out of school early. This amounts to a $65 \%$ increase the likelihood of being held back.

Panel B of table 7 provides estimates obtained when using the rest of the National Capital Region, instead of Quezon City, as a comparison for Manila. Under the assumption of common trends between Manila and the rest of the NCR (column 2), the results indicate a negative effect of family size on repetition, but this effect is not precisely estimated and not significantly different from zero. On the contrary, column 3 indicates a positive and statistically significant effect of family size on the probability of repetition. The point-estimate is indeed very close, in this case, to the same specification in the Manila vs. Quezon City comparison.

All in all, these results indicate a sizable effect of family size on school achievement and a significant trade-off between child education and child quantity. One should however stress that, in the IV estimation, this effect is estimated on households who are affected by the ban, in the sense that they would not have had additional children if the contraceptives had been available as usual. This sample might substantially differ from the whole sample since poorer women are more likely affected by the increase in provision cost, for instance. This might in particular explain the difference between the OLS and 2SLS estimates. To document this point, we compare the characteristics of the compliers with the rest of the population in section 5.2 .

\section{Robustness and external validity}

\subsection{Placebo tests}

Results in the previous section rest on the exclusion restriction that children born to younger women would have had similar outcomes than children born to older women in the absence of the ban. This hypothesis could be violated if mother's age is associated with unobserved covariates and that this asso- 
ciation is specific to Manila in 2007. ${ }^{18}$ Although our exclusion restriction cannot be directly tested, it is possible to assert its validity by conducting various placebo tests. The first approach consists in using two control groups in order to check whether the effect could be driven by changes in fertility choices and educational outcomes related to mothers' age. Along these lines, we proceed with an estimation similar to the one implemented in the previous section but use Quezon City as a placebo treatment group and the other cities as the control group. The estimates are provided in Panel A of Table 8. In this estimation, our instrument, Quezon city $\times$ Mother's age $\times 2007$ is not significantly different from 0 neither in the first-stage nor in the reduced form. The F-statistic is very low and this leads to a very imprecise estimate in the 2SLS. This indicates that when comparing Quezon City and the rest of the NCR, there was no change in fertility nor educational outcomes that varied with mother's age.

The second placebo test consists in comparing Manila and Quezon City at dates when the ban had not yet taken place. We implement this placebo test using the 1990 and 1995 censuses. The results are provided in Panel $\mathrm{B}$ of Table 8. We find a significant effect of the instrument Mother's age $\times$ Manila $\times 1995$, however the effect is positive rather than negative. This indicates a change in fertility behavior that differs between Manila and Quezon City. While average fertility decreased in both cities in 1995 compared to 1990, Manila women appear to have postponed their fertility more than Quezon City women : earlier in life, they appear to have less children, in 1995, than their Quezon counterpart, although their number of children rises with age more rapidly, ending up in a similar total number of children around age 40. Under the assumption that this discrepancy in the change also holds for the 1995-2007 period, our estimates of the effect of the ban on fertility are biased downward. In addition, this might jeopardize our identification if this discrepancy in the change in the fertility pattern came along with differences between Quezon City and Manila in the evolution of parenting norms or in the allocation of resources to children that might have affected children's educational success. This scenario seems rejected by the estimation results given in column 2, panel B : in the reduced form, the difference between Manila and Quezon City, in the change over time in educational success seems independent from mother's age.

Lastly, our third placebo test replaces mother's age by father's age. Indeed, we expect little fertility effects that would be related to the father's age (although they could exist). However, the age of the parents in general could generate spurious effects if older parents were in a better or worse position to take care of their children, or if, as discussed in the previous paragraph, changes in fertility behaviors had taken place in the period under study. The results are provided in Panel $\mathrm{C}$ of table 8. They show that

\footnotetext{
${ }^{18}$ Remember though that we control for Child's age $\times$ Manila $\times 2007$.
} 


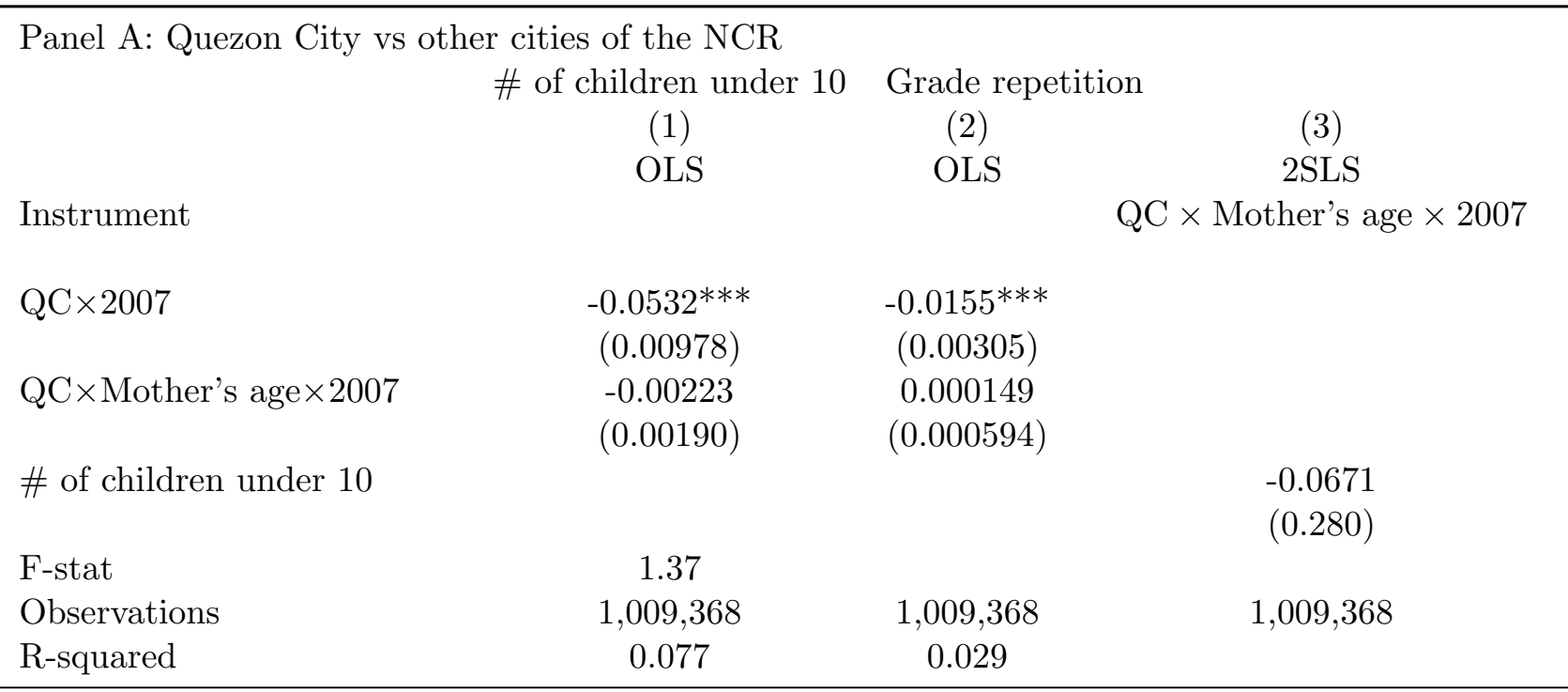

Panel B: Manila vs QC, 1990-1995

\section{\# of children under 10}

OLS

Instrument

Manila×1995

Manila $\times$ Mother's age $\times 1995$

\# of children under 10

$\begin{array}{cc}-0.0282^{* *} & 0.00257 \\ (0.0121) & (0.00383) \\ 0.00702^{* * *} & 0.000887 \\ (0.00250) & (0.000793)\end{array}$

(2)

OLS

2SLS

Manila $\times$ Mother's age $\times 1995$

0.111
F-stat

Observations

R-squared
7.85

386,382

0.090
386,382

0.026
$(0.159)$

Panel C: Manila vs QC, 1995-2007 \# of children under 10

OLS

Instrument

Manila×2007

$0.0614^{* * *}$

$(0.0124)$

$-0.00139$

$(0.00140)$

\# of children under 10

Grade repetition

OLS

2SLS

Manila $\times$ Father's age $\times 2007$

Manila $\times$ Father's age $\times 2007$

$0.0160 * * *$

$(0.00396)$

0.000224

$(0.000444)$

386,382

F-stat

0.99

Observations

399,552

399,552

0.086

0.028

399,552

Note: Standard errors in parentheses. ${ }^{* * *} \mathrm{p}<0.01,{ }^{* *} \mathrm{p}<0.05, * \mathrm{p}<0.1$. Additional controls include: child's age,
its square, child's age interacted with the Manila dumm2 ${ }^{2}$ and interacted with Treatment $\times$ Post, child's gender, mother's age, year and city fixed effects and the interaction Treatment $\times$ Post; where Treatment is QC in Panel A and Manila in Panels B and C; Post is 2007 in Panels A and C, and 1995 in Panel B. The F-stats in column (1) test for the significance of the instrument. 
the interaction Father's age $\times$ Manila $\times 2007$ does not affect the size of the sibship nor the elder children's outcomes.

All these placebo tests point to the conclusion that the identified effect is indeed the one we claim.

\subsection{Compliers}

As previously stated, the effect identified with this strategy is the one that prevails for women who have been affected by the ban. However, we do not necessarily expect women to have been homogenously affected by the ban. Indeed, some women may have had access to contraception despite the ban, through purchases from private providers or from neighboring cities and may have found ways to terminate undesired pregnancies. The heterogeneity of the effect also depends on the willingness of women to use contraception. Both of these effects are likely to be correlated with women's education and income. Understanding who are the compliers will also give us some insight on whether women who managed to avoid an increase in their fertility are those who value the most child quality.

Table 9 provides first-stages estimations for different sub-groups of the population. We consider three different characteristics : whether the child under study is a male, whether the mother has high level of education (more than 10 years of education) and whether the father has high level of education. It allows to determine which families where most likely affected by the ban. The first panel indicates that the ban has a larger effect on fertility when the child under study is a female: this could be due to parental preferences for daughters ${ }^{19}$. Regarding parental education: the first line of the second panel shows that fertility trends were very different between the lower education and the higher education populations. The second line displays evidence that the effect of the ban was stronger for educated women than for the others. A similar conclusion regarding father's education is reached when considering the third set of estimations. Those results are likely driven by the fact that contraceptives are predominantly used by households who are, on average, richer and more educated. As a consequence, they are the ones whose fertility is impacted by the ban. This seems to rule out the possibility that only women with lower preferences for child quality have been impacted by the ban.

Our estimation of the quality-quantity trade-off relies on individuals who were born to families with higher levels of education and whose mothers were younger than in the average household. This raises the question of whether we expect the tradeoff found in such households to be representative of the average effect of sibship size on child's educational attainment. First, those households with 10 years or more of education constitutes two thirds of our

\footnotetext{
${ }^{19}$ Estudillo, Quisumbing, and Otsuka (2001) points to greater investments in girls' schooling but this is found on rural Philippines.
} 
Table 9: Compliers: effect of the ban by subpopulations (Manila vs Quezon City)

\begin{tabular}{lcc}
\hline \hline & \multicolumn{2}{c}{ Number of children under 10} \\
& Male children & Female children \\
Manila x 2007 & $0.0299^{*}$ & $0.0815^{* * *}$ \\
& $(0.0171)$ & $(0.0174)$ \\
Manila x Mother's age x 2007 & $-0.00603^{*}$ & $-0.0147^{* * *}$ \\
& $(0.00343)$ & $(0.00351)$ \\
Observations & 221,610 & 211,412 \\
R-squared & 0.084 & 0.084 \\
\hline & Educated mothers & Uneducated mothers \\
Manila x 2007 & $0.0282^{* *}$ & $0.0994^{* * *}$ \\
Manila x Mother's age x 2007 & $(0.0135)$ & $(0.0261)$ \\
& $-0.0121^{* * *}$ & -0.00684 \\
Observations & $(0.00275)$ & $(0.00511)$ \\
R-squared & 306,278 & 123,693 \\
& 0.087 & 0.079 \\
Manila x 2007 & Educated fathers & Uneducated fathers \\
Manila x Mother's age x 2007 & $0.0309^{* *}$ & $0.0912^{* * *}$ \\
& $(0.0140)$ & $(0.0285)$ \\
Observations & $-0.0124^{* * *}$ & $-0.00992^{*}$ \\
R-squared & $(0.00285)$ & $(0.00564)$ \\
\hline \hline
\end{tabular}

Note: Standard errors in parentheses. ${ }^{* * *} \mathrm{p}<0.01{ }^{* *} \mathrm{p}<0.05,{ }^{*} \mathrm{p}<0.1$. Mother's age is centered at 38 . The effect of the ban $($ Manila $\times 2007)$ is computed for an 11 years old child. Additional controls include: child's age, its square, child's age interacted with the Manila dummy and interacted with Manila $\times 2007$, child's gender, mother's age and year and city fixed effects. 
sample. Second, Becker and Tomes (1976) discuss how the quality-quantity trade-off is likely to vary with household income and suggest that the qualityquantity trade-off is likely to be higher among low-income family. This could explain why studies based on rich countries fail to find any significant trade-off contrary to our study. In that case, the trade-off estimated in this paper would be a lower bound of the average trade-off in the Philippines population.

\section{Conclusion}

In this paper, we use a unique natural experiment to evaluate the Beckerian trade-off between child quality and child quantity. We find substantial effects, contrary to what is usually found by papers who rely on twin births or same-sex births as instruments for family size. Children older than 11 and younger than 16 are $13 \%$ points more likely to repeat a grade or drop out of school early if they have one additional younger sibling.

These sizable effects of the increase in the number of children may arise from a variety of channels. In particular, it may capture both "pure" family size effects, as well as birth-spacing effects. Over the 10 years period of exposure to the reform, children in families affected by the ban experienced both a rise in total family size and a decrease in the spacing between their birth and the one of their siblings. In principle, it would be interesting to isolate both effects, as it would allow to determine what type of family resources constrain investment in children : if these resources are dominantly transferable over time, as could be the case for income, one would expect that only total size should matter; on the contrary if the key resources are period specific resources, as is the case of parental time, birth spacing should also matter. However, one should stress that policy reforms aimed at improving access to contraception are likely to trigger both effects simultaneously. Indeed, our estimates precisely capture the overall effect one could expect from such policies.

This suggests that additional evidence should be collected on the quantityfor-quality trade-off before concluding that it does not prevail and particularly so for poorer countries. From a methodological perspective, it is difficult to be conclusive on the discrepancy between our results and those obtained using other instrumental variables approaches. Rosenzweig and Zhang (2009) have already pointed out the limitations of using instruments such as twins births and sibling sex composition. To benchmark our results, we would ideally like to mimic such strategies but we are not in the position to do so: we do not have information in the census on twins (and the sample in the other data sets is too small) and we do not observe the full sibship, which prevents us from using the sibling sex composition. ${ }^{20}$ In any case, the

\footnotetext{
${ }^{20}$ We have tried to use the assumption that children who declare the same age are twins,
} 
observed discrepancy can be explained by at least three differences. First, it could be that the reinforcement strategy associated to twins is much more important than in our natural experiment. In this case, our estimate is a much closer estimate of the trade-off for the whole sibship than are those based on the usual instruments. Second, our Local Average Treatment Effect estimate might rely on a very different subpopulation. In any case, our estimated effect points to a very substantial trade-off at least for loweducated families, which suggests that economic policies aiming at helping household control their fertility would have strong effects in poor countries. Finally, it could also be that most of the countries that have been studied so far provide child benefits which temper the observed trade-off, while this is not the case in the Philippines.

as is done in Ponczek and Souza (2012) on Brazil, but the size of families is much greater in the Philippines and the birth interval is much shorter. The share of "twins" obtained by this methodology is far too high to be credible. 


\section{References}

Angrist, Joshua D., Victor Lavy, and Analia Schlosser. 2005. "New Evidence on the Causal Link Between the Quantity and Quality of Children" NBER Working Papers 11835 National Bureau of Economic Research, Inc.

Becker, Gary. 1960. "An Economic Analysis of Fertility" in Demographic and Economic Change in Developed Countries, ed. National Bureau Committee for Economic Research Princeton University Press.

Becker, Gary, and H. Gregg Lewis. 1973. "On the Interaction between the Quantity and Quality of Children" Journal of Political Economy 81: S279 $-\mathrm{S} 288$.

Becker, Gary, and Nigel Tomes. 1976. "Child Endowments and the Quantity and Quality of Children." Journal of Political Economy 84: 143-162.

Black, Sandra E., Paul J. Devereux, and Kjell G. Salvanes. 2005. "The More the Merrier? The Effect of Family Size and Birth Order on Children's Education" The Quarterly Journal of Economics 120: 669-700.

Cáceres-Delpiano, Julio. 2006. "The Impacts of Family Size on Investment in Child Quality" Journal of Human Resources 41.

Center for Reproductive Rights. 2007. Imposing Misery: The Impact of Manila's Ban on Contraception.

Conley, Dalton, and Rebecca Glauber. 2006. "Parental Educational Investment and Children's Academic Risk: Estimates of the Impact of Sibship Size and Birth Order from Exogenous Variation in Fertility" Journal of Human Resources 41.

Darroch, Jacqueline E., Susheela Singh, Haley Ball, and Josefina V. Cabigon. 2009. "Meeting Womenś Contraceptive Needs in the Philippines" In Brief 1 Guttmacher Institute.

Estudillo, Jonna P., Agnes R. Quisumbing, and Keijiro Otsuka. 2001. "Gender Differences in Land Inheritance and Schooling Investments in the Rural Philippines" Land Economics 77: 130 -143.

Joshi, Shareen, and T. Paul Schultz. 2007. "Family Planning as an Investment in Development: Evaluation of a Program's Consequences in Matlab, Bangladesh" Working Papers 951 Economic Growth Center, Yale University.

Juarez, Fatima, Josefina Cabigon, Susheela Singh, and Rubina Hussain. 2005. "The Incidence of Induced Abortion in the Philippines: Current Level and Recent Trends" International Family Planning Perspectives 31: 140-149. 
Kumar, Santosh, and Adriana Kugler. 2011. "Testing the Children QuantityQuality Trade-Off in India" MPRA Paper 42487 University Library of Munich, Germany.

Li, Hongbin, Junsen Zhang, and Yi Zhu. 2008. "The Quantity-Quality Tradeoff of Children in a Developing Country: Identification Using Chinese Twins" Demography 45: 223-243.

Orbeta, Aniceto C. 2005. "Poverty, Fertility Preferences and Family Planning Practice in the Philippines" Discussion Paper 22 Philippine Institute for Development Studies.

Ponczek, Vladimir, and Andre Portela Souza. 2012. "New Evidence of the Causal Effect of Family Size on Child Quality in a Developing Country" Journal of Human Resources 47: 64-106.

Qian, Nancy. 2010. "Quantity-Quality and the One Child Policy: The OnlyChild Disadvantage in School Enrollment in Rural China" Working Papers id:2558 eSocialSciences.

Rosenzweig, Mark R, and Kenneth I Wolpin. 1980. "Testing the QuantityQuality Fertility Model: The Use of Twins as a Natural Experiment" Econometrica 48: 227-40.

Rosenzweig, Mark R., and Junsen Zhang. 2009. "Do Population Control Policies Induce More Human Capital Investment? Twins, Birth Weight and China's One-Child Policy" Review of Economic Studies 76: 11491174 . 
Table 10: Descriptive statistics on the main sample

\begin{tabular}{lcccc}
\hline \hline & Mean & Std Deviation & Min & Max \\
& & & & \\
Grade repetition & 0.20 & 0.40 & 0 & 1 \\
\# children under 10 & 1.32 & 1.29 & 0 & 12 \\
Child's age & 13.46 & 1.70 & 11 & 16 \\
Manila & 0.40 & 0.49 & 0 & 1 \\
Mother's age & 38.59 & 3.40 & 31 & 46 \\
Male & 0.51 & 0.49 & 0 & 1 \\
Dummy for 2007 & 0.52 & 0.49 & 0 & 1 \\
Father's age & 41.72 & 5.87 & 31 & 60 \\
Mother has 10 yrs of education & 0.71 & 0.45 & 0 & 1 \\
Father has 10 yrs of education & 0.74 & 0.44 & 0 & 1 \\
\hline \hline
\end{tabular}

Note: descriptive statistics are computed on the same sample as the main estimations. 